University of Nebraska - Lincoln

DigitalCommons@University of Nebraska - Lincoln

Faculty Publications, Department of Psychology

Psychology, Department of

January 1971

\title{
Cheating as a Function of the Labeling of Natural Arousal
}

Richard A. Dienstbier

University of Nebraska-Lincoln, rdienstbier2@unl.edu

Pamela Osbourne Hunter

University of Nebraska-Lincoln

Follow this and additional works at: https://digitalcommons.unl.edu/psychfacpub

Part of the Psychiatry and Psychology Commons

Dienstbier, Richard A. and Osbourne Hunter, Pamela, "Cheating as a Function of the Labeling of Natural Arousal" (1971). Faculty Publications, Department of Psychology. 300.

https://digitalcommons.unl.edu/psychfacpub/300

This Article is brought to you for free and open access by the Psychology, Department of at DigitalCommons@University of Nebraska - Lincoln. It has been accepted for inclusion in Faculty Publications, Department of Psychology by an authorized administrator of DigitalCommons@University of Nebraska - Lincoln. 
Published in Journal of Personality and Social Psychology, 17:2 (1971), pp. 208-213. Copyright (C) 1971 American Psychological Association. Used by permission. "This article may not exactly replicate the final version published in the APA journal. It is not the copy of record.” http://www.apa.org/journals/

\title{
Cheating as a Function of the Labeling of Natural Arousal
}

\author{
Richard A. Dienstbier and Pamela Osborne Hunter \\ University of Nebraska-Lincoln
}

\begin{abstract}
One hundred and five college freshmen were given one of two different side-effects lists associated with a placebo pill. In a "second" experiment, subjects experienced failure on a vocabulary test, supposedly predictive of college success, and received an opportunity to cheat on the test by changing answers. Although it was anticipated that all subjects who considered cheating would experience some arousal, it was predicted that those subjects told to expect drug-induced side effects related to sympathetic arousal would not label their experienced arousal as fear or guilt, and would cheat more than the subjects who anticipated benign side effects. Of the subjects expecting arousal side effects, $49 \%$ cheated, as compared with $27 \%$ of the control subjects $(p<.025)$. Sex differences and implications for theoretical approaches to emotion and conscience are discussed.
\end{abstract}

The relationship between emotional arousal and avoidance has received extensive investigation by psychologists of several theoretical traditions. Through various avoidance paradigms, investigators within the behaviorist tradition have repeatedly demonstrated that animals will abstain from various behaviors after negative emotion has been conditioned to associated cues; the role of arousal in avoidance is clearly supported.

Support for the analogy from animal avoidance to conscience has not, however, been consistently generated by research with human subjects. Often theoretically related to the psychoanalytic tradition and utilizing the constructs of guilt, fear, and anxiety, scores of studies with children have failed to establish that patterns of transgression avoidance are clearly related to the experience of negative emotional arousal in those situations.

A third recent approach to this problem has, however, again lent support to the notion of the arousal-avoidance relationship in moral behavior in humans. This research has approached the arousal-avoidance relationship through techniques of artificially inducing and/or suppressing sympathetic arousal through the use of drugs.

Correspondence should be sent to Richard A. Dienstbier, Department of Psychology, University of Nebraska-Lincoln, Lincoln, Nebraska 68508. The authors are grateful to Monte M. Page for helpful comments on the original draft of this paper.
Since the present research is closely related to this approach, a detailed review of this research will be presented. Using psychopathic and nonpsychopathic subjects selected from prison populations, Schachter and Latane (1964) demonstrated that the psychopaths learned the avoidance of punished errors over nonpunished errors only when injected with adrenalin. Schachter and Latane concluded that psychopaths, usually considered to be low in emotional reactivity, seem insensitive to normal changes in sympathetic arousal. Only when such arousal is artificially heightened beyond its normal range do psychopaths respond in a manner similar to nonpsychopathic subjects in avoiding punished errors. Schachter and Ono (Schachter \& Latane, 1964) tested the effects of a sympathetic inhibitor (the tranquilizer, chlorpromazine) in a situation in which subjects could cheat on a test. Subjects cheated more after having taken chlorpromazine than did a placebo control group, a difference found to be statistically significant when a subgroup of the most physiologically responsive (to chlorpromazine) subjects were compared with the placebo controls. Taken together, these results indicated substantial evidence that sympathetic arousal facilitates avoidance, while sympathetic inhibition or relaxation disinhibits a learned avoidance response, allowing such responses as cheating.

Other work from the Schachter group suggested to the present experimenters, however, that 
the arousal-avoidance relationship might be more complex. First, Schachter and Singer (1962) demonstrated the role of cognition in labeling or interpreting emotional arousal. Adrenalin-induced arousal was interpreted or labeled and responded to differently when subjects expected drug-induced arousal symptoms, than when they perceived their symptoms to be self-generated (as an apparent result of their involvement in an emotion-arousing situation). Second, a provocative study by Nisbett and Schachter (1966) indicated that as a result of presenting differential information concerning arousal symptoms, shock-induced arousal could be interpreted or labeled differently by subjects in the different experimental conditions. After taking a placebo, subjects who were led to expect side effects normally associated with sympathetic arousal (heart palpitation, hand tremor, stomach butterflies) could tolerate far more shock than could other placebo subjects who anticipated benign side effects, irrelevant to emotional arousal. Since the shock-induced arousal was apparently equal for these two placebo groups, differences between the groups in shock tolerance seem due to the decreased inhibiting effects of the (pill-associated) arousal experienced by the sympathetic-symptom placebo group.

This study was undertaken in order to establish whether the arousal-avoidance relationship in moral behavior (cheating) should be extended to consideration of the specific label which is applied to the arousal in understanding or interpreting it. That is, it was hypothesized that it is not emotional arousal per se which influences one to inhibit or avoid cheating, but one's interpretation of the meaning and significance of that arousal.

It was theorized that after the tempted individual detects the possibility of cheating, his consideration of that possibility and/or the possibility of getting caught results in the development of emotional arousal experienced as guilt or fear. The individual can interpret the resultant feelings as a small sample of the emotion he is likely to experience if he succumbs to temptation (in the case of guilt), or as an index of how dangerous the situation will be if he succumbs (in the case of fear). Appraisal of the emotional arousal in that manner would then tend to inhibit cheating. If, however, the individual were led to believe that the arousal he experienced in the temptation situation was drug induced, then he would not be as likely to interpret his feelings as fear or guilt, and the inhibiting effect of that arousal would be reduced. By using a paradigm in which two groups of experimental subjects were equally tempted to cheat, it was specifically hypothesized that subjects who expected arousing side effects from a (placebo) drug would cheat more than control subjects who did not expect arousing side effects from their (placebo) drug.

\section{METHOD}

\section{Subjects}

One hundred and five men and women basic psychology students at the University of Nebraska volunteered for this study in order to fulfill a research participation requirement associated with that course. The form on which the subjects signed up for the experiment indicated that the study would test the effects of a vitamin supplement on vision, and that they would therefore be required to take a capsule containing the vitamin supplement during the course of the study. By conducting the study during the first 4 weeks of the semester, and by using freshmen subjects, it was hoped that suspiciousness associated with sophisticated knowledge of placebos and demand characteristics would be minimized. The study was the first experimental participation for almost all of the subjects.

\section{Procedure}

Placebo manipulations. Subjects participated in small groups of 6-10, with each subject isolated from all others by booths. Each group was composed of either all men or all women, with subjects within each group being randomly assigned to the two experimental conditions.

After seating themselves in booths and receiving verbal instructions that the possible side effects of the drug were mild and harmless, subjects were administered the placebo pill (gelatin) with water and instructed further to read a formal statement of the specific side effects they might experience. The form each subject read introduced the drug either as suproxin, with side effect symptoms of "a pounding heart, hand tremor, sweaty palms, a warm or flushed face, and a tight or sinking feeling in the stomach" (presented as in the Schachter \& Singer, 1962, research) or as the drug supraxin, with side effects of "an increased tendency to yawn, a lessening of eye blink rate, and 'tired eyes." Subjects were required to initial the side effects form after it was read and understood.

It was expected that the suproxin side effects adequately described the physical symptoms associated with sympathetic arousal. It was anticipated that the side effects associated with supraxin would be irrelevant to any real symptoms of arousal which the subjects might experience.

Temptation task. The subjects were told that there would be a I5-minute delay before it would be possible to do any testing of the drug's visual effects, since it would 
take about that long for the drug to take effect. In the meantime, the subjects were to participate in the standardization of a vocabulary test. The cover story indicated that the vocabulary test had been chosen to fill this time gap "in order to help out the people in the Educational Psychology Department." It was suggested that the test was highly predictive of success in college, and had been developed for use with freshmen for that purpose. The test was then introduced by reading the formal instructions, which were designed to make high performance on the test important enough to the subjects so they would be tempted to cheat in order to boost their score (when later given an opportunity). In the course of the formal instructions to the test, the subjects were told to enter their phone numbers or local addresses on their answer sheet. It was explained:

This information is in case you score much lower than average freshmen on the test. Few successful college students score less than 20, as freshmen. In case any of you do, the board of psychologists who have developed this test would like to question you about your subnormal performance. ... You will be contacted by the board, in other words, only if you miss more than 10 items.

The vocabulary test was made difficult by including words which, though familiar, are often misused. (Although only three multiple-choice options were given for the meaning of each of the 30 words, only one noncheating subject got over 19 words correct.)

Visual-perception task. The 10-minute vocabulary test was followed by the visual-perception task, which the subjects thought to lie the heart of the experiment. The task required the subjects to observe a pinpoint source of light in the then darkened room and to indicate by writing a code letter on a blank sheet of paper (in the dark) whether and how the light appeared to be moving at the end of each of three 30 -second periods. When viewed in this manner, the autokinetic effect usually observed is striking, (Only five subjects indicated that they did not see the light move.) Although this part of the experiment was conducted with subjects still seated in their individual booths, the autokinetic apparatus (a camera with a small light bulb inside) was covered prior to the room lights being turned off. When the room lights were again turned on, the subjects could easily identify the camera to be the source of the pinpoint light and could plainly see that nothing could have moved the camera. This effect was engineered in order to provide validation of the pill's effects. Many subjects indicated amazement that they could be so effected.

Increasing side-effect salience. After the autokinetic phase, the experimenter announced that 9 minutes remained before the next important phase of the experiment, and that next phase concerned a self-rating of the drug side effects. In order to make drug side effects salient for the subjects during the ensuing time period, the subjects were asked to look at that rating form which they would use in 9 minutes "so they could complete the rating quickly when called upon to do so." The form asked suproxin subjects to rate their pulse rate, skin perspiration level, warm feelings of the face, and stomach feelings. The form provided to the supraxin subjects required ratings on yawning, eye blink rates, and eye fatigue.

Cheating opportunity. Subjects were told that they could look over the correct answers to their vocabulary test in the remaining minutes before filling out the side-effects form. They were subtly reminded of the threat of "going before the board" if they missed over 10 items, and they were formally warned: "Do not change any answers." Informally, however, they were cautioned to make sure that their answers were dark enough for accurate machine grading, and to insure that any erasures they had previously made were clean. This procedure gave all subjects an excuse to use their pencils on their answer paper.

In order to maximize the opportunity for subjects to change answers, the experimenter was called out of the room by a long-distance call (following the ringing of a distant phone). In the muted discussion which followed, the "secretary" (the second experimenter), who had informed the experimenter of the call, was asked to stay with the subjects, in order to be able to tell them when their time was up (and the side-effects form was to be filled out) "in case the experimenter could not return in time." This ploy was meant to reduce any constraints against cheating associated with the presence of the experimenter.

Shortly after the experimenter returned, he announced that it was time to fill out the side-effects form, followed by a four-page postexperimental questionnaire. The questionnaire asked the subjects what they thought of the visual and side effects of the drug, what their impression of the purpose of the experiment was, whether they thought the vocabulary test was related to the drug part of the study, and, if so, how and when.

Following the completion of those forms, subjects were completely debriefed concerning the nature of the study, assured that their names would be dissociated from their data (in case they did cheat), and sworn to secrecy.

Detection of cheating. In their classic studies on honesty, Hartshorne and May (1928) used a cheating-detection technique of including a piece of waxed paper within a test booklet; corrections made after the answer paper had been detached from the test booklet could then be detected since they would not be indicated on the waxed-paper copy. A similar procedure was used in this study to detect cheating. Two sheets below the standard machine-gradeable answer paper of the test booklet was a sheet of pressure-sensitive white-bond paper (a 3M Company product). All original answers marked on the answer paper were duplicated on the pressure-sensitive paper. Immediately below the answer paper, and covering the pressure-sensitive paper, was a sheet which indicated the correct answers to the vocabulary test. In order to look over the correct answers, subjects were instructed to remove their answer paper from the rest of the test booklet. Any changes made on the answer paper after its removal were not rerecorded on the pressure-sensitive paper. Since the remainder of the test booklet (with various dummy sheets) was sealed shut below the answer paper, it was not possible for the subjects to detect the answer duplication. 


\section{RESULTS}

The data from 7 subjects were dropped because they were unreadable (it was impossible to determine whether cheating had occurred); 3 subjects were eliminated because they indicated suspiciousness on the postexperimental questionnaire that the study might pertain to cheating. Neither drop criterion eliminated subjects differentially from the two experimental groups. None of the 3 subjects who indicated suspiciousness had cheated. The data from 95 subjects (46 men and 49 women) were used.

Whether cheating was defined as changing any answer or whether defined as changing enough answers so that at least 20 items were correct (the point at which the subject would not have to "go before the board"), the prediction of the experiment was confirmed. Subjects cheated more in the suproxin condition when they could attribute any emotional arousal feelings they might have experienced to that drug. Table 1 indicates the number of subjects who cheated in each of the two experimental conditions according to the two cheating criteria defined above.
Overall, $37.9 \%$ of the subjects changed at least one answer; that percentage of cheaters remained relatively constant across sex, with rates of $37.0 \%$ and $38.8 \%$ for men and women, respectively.

The data of Table 1 indicate that the magnitude of the difference in rate of cheating between the two experimental groups is greatest when cheating is defined as changing answers to a criterion of 20 correct. This would suggest that not only did more individuals change answers in the suproxin condition, but of those who changed any answers in the two conditions, suproxin cheaters changed more answers, per person, than did supraxin cheaters. A check on that relationship by one-tailed $t$ test indicated that for men subjects only, the mean of 8.50 changed answers for suproxin cheaters was significantly greater $(t=2.22, p<.025)$ than the mean of 3.50 changed answers for the supraxin cheaters. No such relationship between number of answers changed and drug description existed for women cheaters.

Finally, the questions concerning drug side effects showed no trends large enough in magnitude to indicate any reliable information, except that subjects indicated they felt more of the side

Table 1 Classification of Subjects as Cheaters and Noncheaters by Condition

\begin{tabular}{|c|c|c|c|c|c|c|c|c|}
\hline \multirow[t]{2}{*}{ Condition } & \multicolumn{4}{|c|}{$\begin{array}{l}\text { Cheating defined as } \\
\text { changing any answers }\end{array}$} & \multicolumn{4}{|c|}{$\begin{array}{l}\text { Cheating defined as } \\
\text { changing enough answers } \\
\text { to reach criterion of } 20 \text { correct }\end{array}$} \\
\hline & Cheaters & Noncheaters & \multicolumn{2}{|c|}{$\%$ cheaters $p^{\mathrm{a}}$} & \multirow{2}{*}{$\begin{array}{l}\text { Cheaters } \\
\text { s combinec }\end{array}$} & \multirow{2}{*}{$\frac{\text { Noncheaters }}{d}$} & \multirow[t]{2}{*}{$\%$ cheaters } & \multirow[t]{2}{*}{$\mathrm{s} \quad p^{\mathrm{a}}$} \\
\hline & & & Men & and wom & & & & \\
\hline Suproxin & 23 & 24 & 49.0 & $<.025$ & 10 & 37 & 21.3 & $<.015$ \\
\hline Supraxin & 13 & 35 & 27.1 & $<.025$ & 2 & 46 & 4.2 & $<.015$ \\
\hline \multicolumn{9}{|c|}{ Men $S$ s only } \\
\hline Suproxin & 13 & 10 & 56.5 & $<.01$ & 7 & 16 & 30.4 & $<.005$ \\
\hline Supraxin & 4 & 19 & 17.4 & $<.01$ & 0 & 23 & 0.0 & $<.005$ \\
\hline \multicolumn{9}{|c|}{ Women $S$ s only } \\
\hline Suproxin & 10 & 14 & 41.7 & $n s$ & 3 & 21 & 12.5 & $n s$ \\
\hline Supraxin & 9 & 16 & 36.0 & $n s$ & 2 & 23 & 8.0 & $n s$ \\
\hline
\end{tabular}

\footnotetext{
${ }^{a}$ Probability levels determined by the Fisher exact test (Hays, 1966) represent one-tailed tests of the hypotheses.

${ }^{\mathrm{b}}$ When defining cheaters as those who change answers to criterion, noncheaters are defined as both those who change no answers and those who change fewer answers than necessary to reach criterion.
} 
effects associated with supraxin (yawning, eye blink rate increases, eye strain, and tiredness) than they did of the effects associated with suproxin. Though not predicted, such changes would follow from the nature of this experiment; subjects had been required to stare at a light in an otherwise totally dark room, followed by the sudden onset of the bright room lights. Blinking and tired eyes are understandable.

\section{DISCUSSION}

\section{Sex Differences}

Although the data by sex of subject in Table 1 suggest that the women subjects were far less responsive than the men to the independent variable manipulation, a chi-square test for heterogeneity indicated that the apparent difference between the sexes was not statistically significant. Nevertheless, the absolute level of the difference between the sexes was large enough to encourage speculation on the possibility of real sex differences. If the assumption is made that women were more test anxious than men in this study (as seems the case in most testing situations), then sex-differences in the present direction are compatible with the results of the Nisbett and Schachter (1966) pain research. In that study, two levels of fear (arousal) were produced; differences in pain tolerance between the two placebo groups (arousal side effects versus benign side effects) did not occur under high-fear conditions. That is, the condition of high fear interfered with the effectiveness of the side-effect labeling variable. It appears that emotion labeling or relabeling based on these rather subtle side-effects lists might be limited to relatively mild levels of arousal. Alternatively, it is possible that arousal level differences between the sexes are insignificant, but that different cognitive tendencies between men and women allow men greater flexibility in interpreting arousal. These explanations are presently offered only as hypotheses; further research is being developed to check these predictions.

\section{Mood Suggestion Problem}

One of the apparent difficulties with the present paradigm is that the listing of the expected arousal side effects to one group of subjects might actually induce the subjects to experience a changed mood or emotion in a manner analogous to direct suggestion. Differences in cheating rates between the subject groups could then be attributed not to the relabeling of naturally occurring emotional arousal, but to direct changes in mood induced by the instructions concerning pill side effects. This question, in concrete form, is whether the suproxin group, having received a list of the expected arousing side effects, was, in fact, more aroused than the supraxin group, and whether this difference in arousal level could account for the differences in cheating observed. The Schachter and Ono (Schachter \& Latane, 1964) results on the effects of chlorpromazine suggest an answer to this question. In that study, arousal was associated with a reduction in cheating - the less aroused state, with an increase in cheating. If a direct-suggestion effect were the cause of the results of this study, the suproxin group would have been expected to cheat less, not more.

\section{Theoretical Relevance}

Although the hypothesis upon which this study is based was derived largely from the experimental work of Schachter and his collaborators, the results of this study may be interpreted as fitting within a theoretical framework going beyond the Schachter work. Arnold (1950) proposed that the emotion cycle begins with a primary appraisal of the situation (e.g., as threatening), followed by autonomic discharge consistent with that primary appraisal; the perception of the peripheral changes resulting from the autonomic discharge, termed the secondary appraisal, then provides further information to the individual about the state and depth of his emotion. (The theory in this form demands no assumptions concerning differential physiological changes for different emotions.) In the present experiment, it was anticipated that as a result of subjects appraising the possibility of cheating, specific emotions (largely fear and guilt) would arise, and that the secondary appraisal of emotional state, resulting from the perception of the accompanying physiological arousal symptoms, would reinforce that primary appraisal for those subjects who expected only the benign side 
effects associated with supraxin. The suproxin group, expecting arousal-relevant drug side effects, was able to make a different secondary appraisal, dissociating any physiological feedback from the experience of true emotion, thus experiencing those normally inhibiting emotions as less intense, hence, less inhibiting.

This paradigm reverses the Schachter and Singer (1962) procedure; in that study subjects used external cues to interpret artificially induced arousal as a specific emotion. The results of the present study indicate that naturally induced specific emotions can be interpreted as nonspecific arousal when subjects are anticipating drug-induced arousal symptoms. Both studies demonstrate the importance of cognitive information in determining the influence that the secondary appraisal will have on the meaning of the emotional experience.

Extending these studies outside the laboratory, at the most general level, they provide support for the notion that cognitive information plays a key role in the interpretation or labeling, and hence, in the effect of emotions, and that even naturally occurring emotion is subject to this apparent ease of reinterpretation. More specifically, in the cheating situation of this study, the suproxin group was provided with a kind of artificial defense - a way of freeing behavior from the constraints of inhibiting emotion. The cheating situation could be seen as a prototype of the way real defenses might sometimes work in real life. Thus, the rationalization that may justify cheating might achieve that effect by allowing the individual to reexperience his fears and guilts as anger or as symptoms of the importance of the situation for him, rather than as an index of impulses which he would normally experience and accept as inhibiting.

\section{References}

Arnold, M. B. An excitatory theory of emotion. In M. L. Reymert (Ed.), Feelings and emotions: The Mooseheart Symposium. New York: McGraw-Hill, 1950.

Hartshorne, H., \& May, M. A. Studies in the nature of character. Vol. 1. Studies in deceit. New York: Macmillan, 1928.

Hays, W. L. Statistics for psychologists. New York: Holt, 1963.

Nisbett, R. E., \& Schachter, S. Cognitive manipulation of pain. Journal of Experimental Social Psychology, 1966, 2, 227-236.

Schachter, S., \& Latane, B. Crime, cognition, and the autonomic nervous system. Nebraska Symposium on Motivation, 1964, 12, 221-275.

Schachter, S., \& Singer, J. E. Cognitive, social, and physiological determinants of emotional state. Psychological Review, 1962, 69, 379-399. 